\title{
Novel gene rearrangements in transformed breast cells identified by high-resolution breakpoint analysis of chromosomal aberrations
}

\author{
Kristian Unger, Johannes Wienberg ${ }^{1}$, Andrew Riches ${ }^{2}$, Ludwig Hieber, \\ Axel Walch ${ }^{3}$, Andreas Brown, Patricia C M O'Brien ${ }^{4}$, Cäcilia Briscoe ${ }^{2}$, \\ Lindsey Gray ${ }^{2}$, Elke Rodriguez, Gerhard Jack ${ }^{5}$, Jeroen Knijnenburg ${ }^{6}$, \\ Giovanni Tallini ${ }^{7}$, Malcolm Ferguson-Smith ${ }^{4}$ and Horst Zitzelsberger
}

\footnotetext{
Helmholtz Zentrum München, German Research Center for Environmental Health (GmbH), Department of Radiation Cytogenetics, Ingolstädter Landstr. 1, D-85764 Neuherberg, Germany

${ }^{1}$ Department Biologie II, Anthropologie und Humangenetik, Ludwig Maximilians Universität, 82152 Martinsried, Germany

${ }^{2}$ Bute Medical School, University of St Andrews, St Andrews, Fife KY16 9TS Scotland, UK

${ }^{3}$ Institut für Pathologie, Helmholtz Zentrum München - Deutsches Forschungszentrum für Gesundheit und Umwelt GmbH, Ingolstädter Landstr. 1, D-85764 Neuherberg, Germany

${ }^{4}$ Cambridge University Centre for Veterinary Science, University of Cambridge, Cambridge CB3 OES, UK

${ }^{5}$ Strahlenbiologisches Institut, Helmholtz Zentrum München - Deutsches Forschungszentrum für Gesundheit und Umwelt GmbH, Ingolstädter Landstr. 1, D-85764 Neuherberg, Germany

${ }^{6}$ Department of Molecular Cell Biology, Leiden University Medical Center, Einsteinweg 20, 2333 ZC Leiden, The Netherlands

${ }^{7}$ Anatomia Patologica, Università di Bologna, Ospedale Bellaria, Via Altura 3, 40139 Bologna, Italy

(Correspondence should be addressed to H Zitzelsberger; Email: zitzelsberger@ helmholtz-muenchen.de)

( $\mathrm{K}$ Unger is now at the Department of Histopathology, Imperial College London, London, UK)
}

\begin{abstract}
Chromosomal copy number alterations and chromosomal rearrangements are frequent mutations in human cancer. Unlike copy number alterations, little is known about the role and occurrence of chromosomal rearrangements in breast cancer. This may be due to the fact that chromosomebased breakpoint analysis is widely restricted to cultured cells. In order to identify gene rearrangements in breast cancer, we studied the chromosomal breakpoints in radiationtransformed epithelial breast cell lines using a high-resolution array-based approach using $1 \mathrm{Mb}$ bacterial artificial chromosome (BAC) arrays. The breakpoints were further narrowed down by fluorescence in situ hybridisation (FISH) with clones from the $32 \mathrm{k} \mathrm{BAC} \mathrm{library.} \mathrm{The} \mathrm{analysis} \mathrm{of} \mathrm{the}$ cell lines B42-11 and B42-16 revealed rearrangements of chromosomes 7, 8, 10 and 12. We identified the genes Has2, Grid1, Ret, Cpm, Tbx3, Tbx5, Tuba1a, Wnt1 and Arf3 within the breakpoint regions. Quantitative RT-PCR showed a deregulated expression of all of these candidate genes except for $T b \times 5$ and $T b x 3$. This is the first study demonstrating gene rearrangements and their deregulated mRNA expression in radiation-transformed breast cells. Since the gene rearrangements occurred in the transformed and tumourigenic cell lines only, it is likely that these were generated in conjunction with malignant transformation of the epithelial breast cells and therefore might reflect early molecular events in breast carcinogenesis. Initial studies indicate that these gene alterations are also found in sporadic breast cancers.
\end{abstract}

Endocrine-Related Cancer (2010) 17 87-98

\section{Introduction}

Chromosome rearrangement is a key mechanism for gene alteration and subsequent deregulation of cellular processes such as proliferation, apoptosis, genome stability, angiogenesis and motility, leading to malignant tumour development (Hanahan \& Weinberg 2000, Albertson et al. 2003). Whereas in breast cancer, numerous studies on copy number alterations exist 
(Climent et al. 2007), there is only little knowledge on the role of chromosomal rearrangements in this type of cancer. This might be due to the fact that highresolution chromosome analysis requires metaphase chromosomes from vital cells, which are not available from archived clinical samples. However, cell culture models are highly informative tools for the investigation of molecular aberrations (Riches et al. 1997, Zitzelsberger et al. 2001, Climent et al. 2007), which moreover can be used for the functional assessment of candidate genes (Neve et al. 2006). This study supports the hypothesis that gene rearrangements observed in radiation-transformed breast cell lines partly mirror those occurring in primary breast cancer. In order to identify such gene rearrangements, we made use of an experimental approach, which combines the detection of chromosomal breakpoints by cytogenetic techniques, high-throughput isolation of aberrant chromosomes using fluorescence-activated chromosome sorting (FACS) and high-resolution mapping of chromosomal breakpoints using $1 \mathrm{Mb}$ bacterial artificial chromosome (BAC) arrays. This approach has already been applied in both cancer and standard clinical cytogenetics (Darai-Ramqvist et al. 2006, Neve et al. 2006, Backx et al. 2007).

In this study, we present a comprehensive analysis of chromosome rearrangements in two radiationtransformed human epithelial breast cell lines showing a tumourigenic phenotype. The identification of rearranged candidate genes by chromosome breakpoint analysis in transformed breast cells and their altered gene expression point to an involvement of these gene rearrangements in the development of breast cancer.

\section{Material and methods}

\section{Cell lines}

Primary cultures of human mammary epithelial cells were established from surgically removed tissue samples from regions remote from the tumour in a patient with breast cancer presenting for mastectomy (Romanov et al. 2001). The cells were grown in mammary epithelial cell growth medium (MEGM) with additives (Lonza, Basel, Switzerland) and immortalised by transduction with the human telomerase catalytic subunit (hTERT). The hTERT gene was cloned into the retroviral vector (pBABE-puro), and supernatants from the packaging cell line $\psi$ CRIP were used to transduce the mammary epithelial cells (Wyllie et al. 2000). A cloned cell line B42-htLG was established following selection with puromycin and subsequently exposed to 20 fractions of 2 Gy gamma irradiation and screened for anchorage-independent growth in soft agar $(0.3 \%)$. In contrast to the irradiated cell line, the parent line B42 does not produce significant numbers of anchorage-independent colonies. Cloned cell lines were established from individual anchorage-independent colonies derived from the irradiated parent cells, from which two cell lines (B42-11 and B42-16) were used for the current experiments. The cell lines were tested for tumourigenicity by s.c. injection into athymic nude mice, which were subsequently monitored for the induction of tumour growth.

\section{Spectral karyotyping}

Metaphase preparations were generated from the radiation-transformed cell lines and from the nontumourigenic parent cell line B42-htLG according to standard procedures (Zitzelsberger et al. 2001). Spectral karyotyping (SKY) analysis was performed as described previously (Zitzelsberger et al. 1999).

\section{Chromosome sorting}

Metaphase chromosomes from cell lines B42-11 and B42-16 were prepared according to standard flow sorting protocols (Ferguson-Smith 1997) with optimised buffers (Ng \& Carter 2006).

Chromosome sorting was performed on a FACS Vantage (Becton Dickinson, Franklin Lakes, NJ, USA) equipped with two water-cooled lasers (Innova 300 and Innova 70, Coherent, Santa Clara, CA, USA) tuned at multi-line u.v. (330-360 nm) to excite Hoechst 33258 and chromomycin A3 $(457 \mathrm{~nm})$. Sorting speed was $\sim 10$ chromosomes/s using a $70-\mu \mathrm{m}$ nozzle tip. For flow karyogram analysis and gating the programme, CellQuest (Becton Dickinson) was used. For each rearrangement, about 500 chromosomes were sorted into PCR tubes.

\section{Amplification of genomic chromosomal DNA}

DNA from chromosomes was amplified using the single cell WGA kit (Sigma) according to the manufacturer's protocol. DNA purity and quantity were determined using a spectrophotometer (NanoDrop Technologies, Wilmington, DE, USA).

\section{Hybridisation of amplified DNA to metaphase spreads}

One microgram of WGA amplification product was labelled with digoxigenin by nick translation, hybridised to normal human metaphase spreads and detected using Cy3-conjugated anti-digoxigenin. FISH signals 
were analysed using an epifluorescence microscope (AxioVision, Zeiss) and captured using the FISHView software (Applied Spectral Imaging, Neckarhausen, Germany).

\section{Array painting}

DNA from aberrant chromosomes (M11-1, M16-1 to -5; Table 1) was hybridised onto $1 \mathrm{Mb} \mathrm{BAC}$ arrays according to Fiegler et al. (2003) in an automated hybridisation and washing station (HS400, Tecan, Männedorf, Switzerland). Slides were scanned using a GenePix Personal 4100A array scanner (Molecular Devices, Sunnyvale, CA, USA), and feature intensities were extracted using the GenePixPro 6.0 software (Molecular Devices). The datasets were normalised using the MANOR package (Neuvial et al. 2006) and segmented using the DNAcopy package (Venkatraman $\&$ Olshen 2007).

\section{Confirmatory fluorescence in situ hybridisation (FISH) analysis of array-painting results}

DNA from BAC clones spanning or flanking the chromosomal breakpoints was labelled either with biotin or with digoxigenin by nick translation according to standard protocols. Hybridisation to metaphase spreads of the tumourigenic cell lines was performed as previously described (Zitzelsberger et al. 2001).

\section{Array CGH}

DNA was extracted from fresh cultured cells (B42-11, B42-16 and B42-htLG) using the DNA mini kit (Qiagen). Totally, $450 \mathrm{ng}$ male genomic reference DNA (Promega) and $450 \mathrm{ng}$ cell line DNA were labelled and co-precipitated with $135 \mu \mathrm{g}$ Cot-1 DNA (Roche) prior to hybridisation. Hybridisation and washing were performed as described above.
Data were normalised and segmented using the R-package MANOR (Neuvial et al. 2006) and DNAcopy (Venkatraman \& Olshen 2007).

\section{Cloning of fusion products using rapid amplification of cDNA ends}

In order to analyse the rearranged sequences of Has2 and Gridl, rapid amplification of cDNA ends (RACE)-PCR (Frohman et al. 1988) was performed. The reactions were carried out according to the manufacturer's protocols using the $3^{\prime}$ and $5^{\prime} \mathrm{RACE}$ systems for RACEs (Invitrogen). Gene-specific 'nested' primers binding within exons 1 and 2 of the gene Has 2 and exon 2 of gene Gridl were used for $3^{\prime}$ RACE analysis, and primers binding within exons 3 and 4 of the gene Gridl and exon 3 of the gene Has 2 were used for $5^{\prime}$ RACE analysis.

The amplification products were cloned into a TOPO cloning vector (Invitrogen) according to the manufacturer's protocol. Transfected clones were checked for inserted DNA using PCR with M13 forward and reverse primers. Clones showing PCR amplicons of the expected size were grown for $14 \mathrm{~h}$ at $37^{\circ} \mathrm{C}$ in $\mathrm{LB}$ medium (ampicillin) followed by a DNA extraction using the Nucleo Plasmid kit (Macherey-Nagel, Düren, Germany). The plasmid DNA was amplified using the BigDye Terminator v3.1 Cycle Sequencing kit (Applied Biosystems, Fosters City, CA, USA) and analysed using an ABI3730 sequencer (Applied Biosystems). DNA sequences were aligned to genomic and cDNA sequences gathered from the Ensembl database using the NTI Vector software (Invitrogen).

\section{RNA isolation and reverse transcription}

RNA was isolated from $\sim 5 \times 10^{4}$ cells by phase separation using Trizol (Invitrogen) and residual DNA was digested using the Turbo DNA-free kit (Ambion, Austin, TX, USA). Five micrograms of total RNA was

Table 1 Summary of marker chromosomes in cell lines B42-11 and B42-16 detected by spectral karyotyping (SKY) and array painting

\begin{tabular}{|c|c|c|c|}
\hline Cell line & Marker & Cytogenetic description (SKY) & $\begin{array}{l}\text { BAC-based description (array painting } \\
\text { with } 1 \mathrm{Mb} \text { BAC clone set) }\end{array}$ \\
\hline \multirow{2}{*}{ B42-11 } & $\mathrm{M} 11-1$ & $\operatorname{der}(7)(7 p t e r \rightarrow q 11.1:: 10 q 11.2 \rightarrow$ qter $)$ & $\operatorname{der}(7)(7 p t e r \rightarrow$ RP5-905H7::RP11-38B21 $\rightarrow$ qter) \\
\hline & M16-1 & $\operatorname{der}(4)(4 p t e r \rightarrow 4 q 31.3:: 12 q 24.2 \rightarrow q$ ter $)$ & der(4)(4pter $\rightarrow$ RP11-28E24::RP11-8A1 $\rightarrow$ qter) \\
\hline \multirow[t]{3}{*}{ B42-16 } & M16-2 & $\operatorname{der}(8)(8 p t e r \rightarrow q 24.1:: 10 q 23.2 \rightarrow$ qter $)$ & $\operatorname{der}(8)$ (8pter $\rightarrow$ RP11-115M9::RP11-396M20 $\rightarrow$ qter) \\
\hline & M16-3 & $\begin{array}{l}\operatorname{der}(10)(12 q 13.1 \rightarrow q 15:: 10 p 11.2 \rightarrow \\
\quad \text { q23.2:8q24.1 } \rightarrow \text { qter })\end{array}$ & $\begin{array}{l}\operatorname{der}(10)(\mathrm{RP} 11-89 \mathrm{H} 19 \rightarrow \mathrm{RP} 11-444 \mathrm{~B} 24:: \mathrm{RP} 13-445 \mathrm{~N} 5 \rightarrow \\
\quad \mathrm{RP} 11-113 \mathrm{E} 21:: \mathrm{RP} 11-96 \mathrm{~B} 2 \rightarrow \text { qter })\end{array}$ \\
\hline & M16-4 & $\begin{array}{l}\operatorname{der}(12)(12 p t e r \rightarrow 12 q 13.1:: 12 q 15 \rightarrow \\
\quad \text { q24.2::10p12.33 } \rightarrow \text { p11.2::8q11.21 } \rightarrow \\
\quad \text { q24.1ter })\end{array}$ & $\begin{array}{l}\text { der(12)(12pter } \rightarrow \text { RP3-417E16::Cancer_3A4 } \rightarrow \rightarrow \text { RP1- } \\
\text { 46F2::RP11-16O1 } \rightarrow \text { CTB-164I22::RP11- } \\
\text { 115M9RP11-567J20 } \rightarrow \text { qter })\end{array}$ \\
\hline
\end{tabular}






reverse transcribed using the Superscript II kit (Invitrogen), and the resulting cDNA was directly used for RT-PCR.

\section{Real-time RT-PCR}

We used commercial exon-spanning Taqman probe sets (Applied Biosystems) for the genes Has2, Grid1, Wnt1, Arf3, Cpm, Tbx3, Tbx5 and $\beta$-actin (reference gene). Reactions $(25 \mu \mathrm{l})$ were carried out in triplicates and under standard cycling conditions ( 40 cycles) in an ABI7300 real-time PCR thermocycler (Applied Biosystems) in combination with the analysis software SDS (Applied Biosystems). Probe sets for exons 10-11 and $12-13$ of the Ret gene were used as previously described (Rhoden et al. 2004).

Relative quantitation was performed using the $\Delta \Delta C(\mathrm{t})$ method (Livak \& Schmittgen 2001). $\Delta-C_{\mathrm{t}}$ values were calculated relative to the $C_{\mathrm{t}}$ of $\beta$-actin and $C_{\mathrm{t}}$ values in the non-transformed B42-htLG (calibrator cell line). If genes were not expressed in the calibrator cell line, expressions are given qualitatively (Table 2).

\section{Validation of gene alterations of Has2, Ret and Grid 1 by FISH analysis of a human breast cancer tissue array}

A human breast cancer tissue microarray (TMA, BRC1501, Pantomics Inc., San Francisco, CA, USA) was hybridised with the following YAC and BAC FISH probes: RP11-115N9/RP11-711N15 (Has2 gene), RP11-369M20/RP11-711N15 (Gridl gene) and CEPH-YAC clones 313F4/214H10/344H4 (Ret gene). The TMA comprised 5- $\mu$ m FFPE sections (in duplicate) of 70 mostly high-grade breast cancers. Hybridisation and analysis of the TMA were performed as described earlier (Unger et al. 2004). For evaluation, fused and separated FISH signals were scored in each cell to detect gene rearrangements (split signals), the wild-type gene (fused signals) or altered copy number (increased or decreased number of FISH signals). FISH signals were counted as split when the distance between the red and the green signal was $>10 \mu \mathrm{m}$.

\section{In silico validation of candidate genes in a public available gene expression set}

In order to validate gene expressions of the found candidate genes, a publicly available gene expression set GSE3494 (Miller et al. 2005) was downloaded from the Gene Omnibus website (http://www.ncbi. nlm.nih.gov/geo/). The cel files that resulted from Affymetrix U133A and U133B Genechip hybridisations were normalised separately using the 
R-package gcrma (http://www.bioconductor.org/ packages/2.0/bioc/html/gcrma.html), combined and clinical data attached. After subsetting data according to clinically meaningful groups (grade, nodal status and estrogen receptor (ER) status) expression values (of candidate genes Has2, Gridl, Ret) were tested group by group for significantly different levels of expression either using Mann-Whitney test in case of testing two groups or using Kruskal-Wallis test in case of testing three groups. The test result was significant when the $P$ value was within the $95 \%$ confidence interval. Plots of expressions along with test results are given in the Supplementary data file, see section on supplementary data.

\section{Results}

We have identified chromosomal rearrangements and copy number alterations in the radiation-transformed breast cell lines B42-11 and B42-16 producing small tumours in nude mice (tumour induction in each of the three mice tested per cell line). No tumours developed from cells of the parent cell line B42-htLG in any of the eight nude mice tested indicating a tumourigenic phenotype for the radiation-transformed cell lines. Copy number changes were detected using $1 \mathrm{Mb}$ BAC arrays, whilst the chromosomal breakpoints were finemapped and confirmed by FISH and mRNA expression levels of the resulting candidate genes were measured by quantitative RT-PCR. Further, we cloned the rearrangement products of the genes Has 2 and Grid1 using RACE.

\section{Isolation of marker chromosomes}

All markers of the cell lines B42-11 and B42-16 identified by SKY (Fig. 1, cytogentic description of cell lines is given in Supplementary data, see section on supplementary data, section 2) were successfully isolated by FACS. A cytogenetic description and a schematic illustration of the marker chromosomes are

A

B42-11
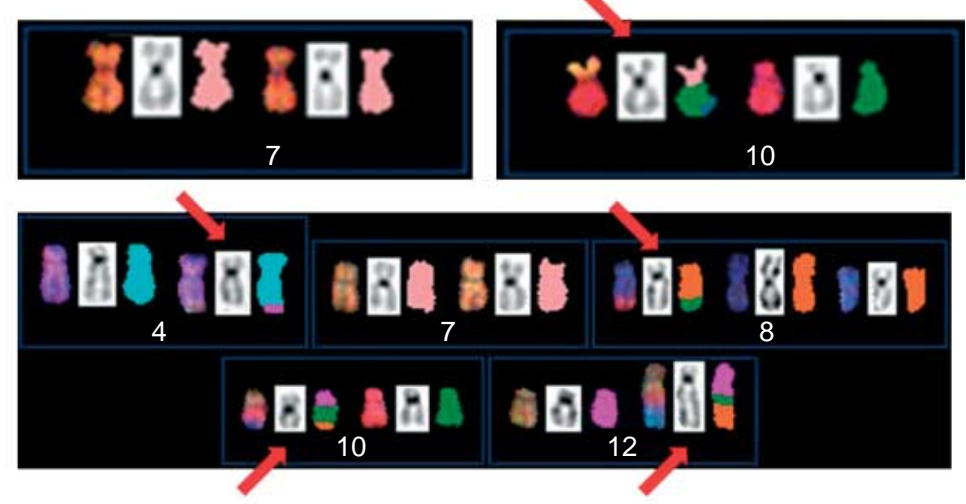

B

B42-16

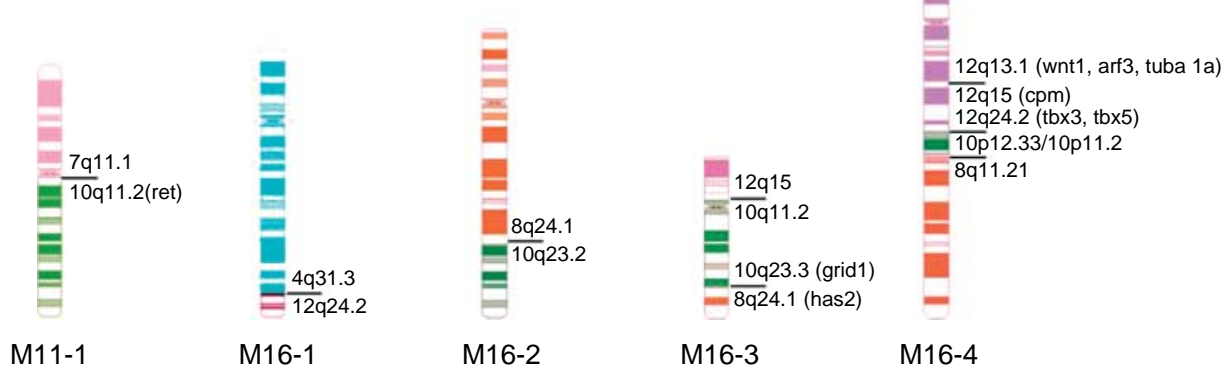

Figure 1 Structural aberrations in the radiation-transformed cell lines B42-11 and B42-16. (A) Marker chromosomes (indicated by red arrows) identified by spectral karyotyping (SKY) in the cell line B42-11 (upper panel) and B42-16 (lower panel). B42-11 shows one marker chromosome M11-1 (mar(7)) and B42-16 marker chromosomes M16-1 (mar(4)), M16-2 (i(8)(q)), M16-3 (mar(10)) and M16-4 (mar(12)). Schematic illustration of chromosomal rearrangements in B42-11 demonstrating a translocation (B) and in B42-16 exhibiting complex exchange aberrations (C). Thin black lines with cytogenetic band designation indicate positions of chromosomal breakpoints. Chromosomal fragments indicated by a red cross are deleted in the cell lines. Blue lines indicate exchange processes between chromosomes at the marked breakpoints. Grey small boxes indicate candidate genes, which may be affected by the chromosomal rearrangement, whilst red arrows indicate elevated mRNA expression. (D) Marker chromosomes of cell lines B42-11 and B42-16 drawn in 500 band resolution according to their ISCN cytogenetic description using the CyDAS online analysis site (http://www.cydas.org/OnlineAnalysis, Hiller B, Bradtke J, Balz H \& Rieder H 2005). 

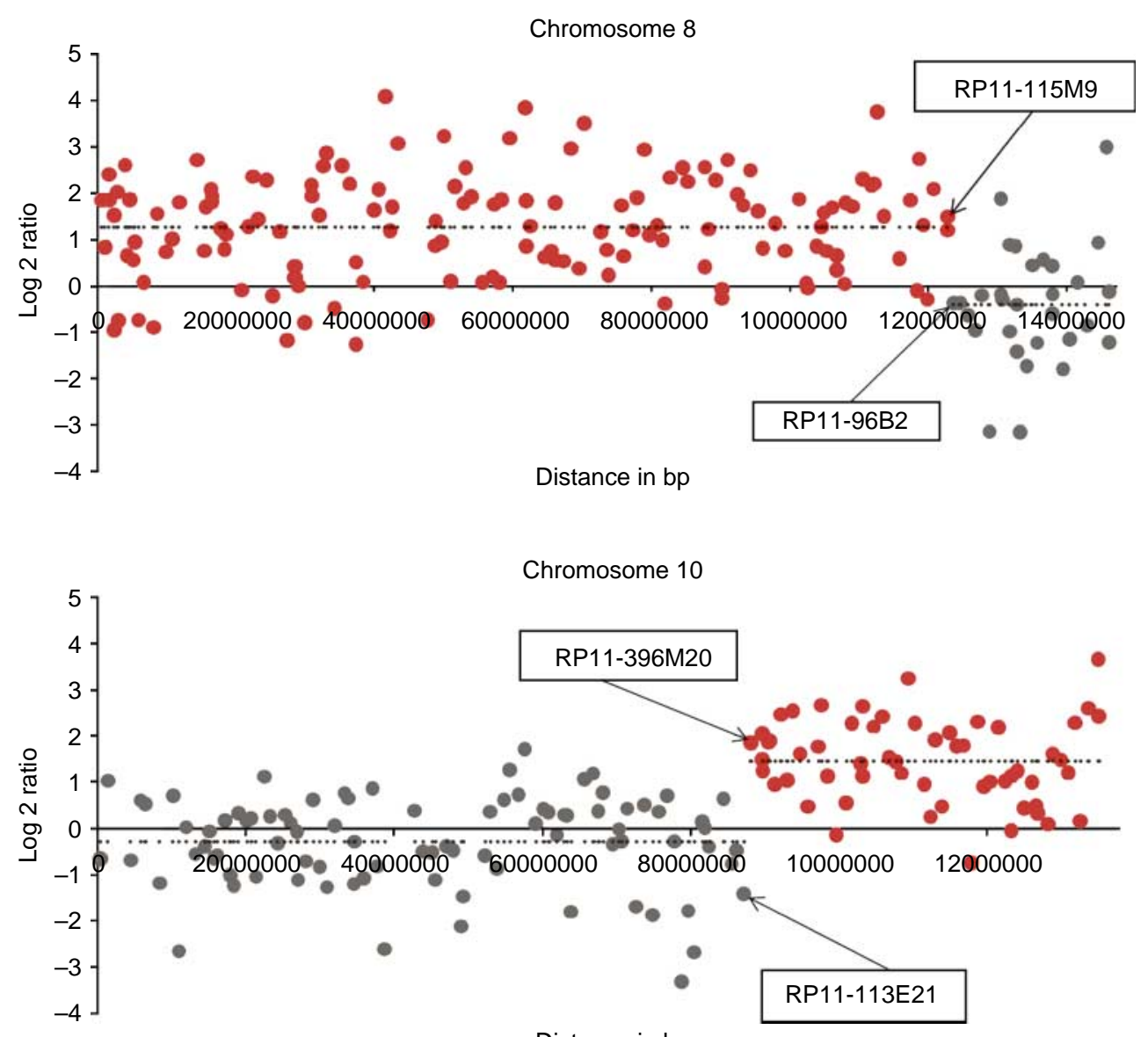

Distance in bp

Figure 2 Array-painting analysis of marker M16-2 (t(8;10)) from cell line B42-16. Array profiles indicate hybridisation signals of the marker chromosome (green dots). BAC clones flanking the breakpoint region are indicated by arrows.

given in Table 1. The DNA of sorted chromosomes was amplified and subsequently FISH hybridised to normal human metaphase spreads in order to verify the origin of the sorted chromosomes. Regions of the metaphase chromosomes showing a hybridisation signal represent the chromosomal composition of the isolated marker chromosomes (data not shown).

\section{Array painting and identification of candidate genes}

In total, six marker chromosomes were cytogenetically characterised by flow-sorting and hybridised to $1 \mathrm{Mb}$ BAC arrays (array painting). An exemplary illustration of such an analysis is given in Fig. 2, while Table 1 summarises the results of the array-painting analyses. The region in between breakpoint-flanking BAC clones (given in Table 1) identified the candidate genes Has2 (chromosome 8), Grid1, Ret (both chromosome 10), Cpm, Tbx3/5, Wnt1 and Arf3 (chromosome 12). These were further investigated by quantitative RT-PCR in order to detect aberrant mRNA expression levels. All chromosome rearrangements were fine-mapped and verified by FISH with BAC clones (Supplementary data, see section on supplementary data) on metaphase preparations of the cell lines. This analysis also revealed the deletion of a small region comprising the gene $T b x 5$, what explains the absent mRNA expression of Tbx5 (Table 2) in the cell line B42-16. A schema showing array-painting results and illustrating exchange processes in both radiation-transformed cell lines is given in Fig. 1.

\section{Array CGH analysis}

All cell lines have been investigated for copy number changes by array CGH using $1 \mathrm{Mb}$ BAC arrays (Table 3). In total, gains on chromosomes 7 and 8 and a loss on chromosome 10 were identified in 
Table 3 Summary of array CGH results

\begin{tabular}{|c|c|c|c|c|c|c|c|}
\hline Chromosome & $\begin{array}{l}\text { Region start } \\
\text { (clone name) }\end{array}$ & $\begin{array}{l}\text { Region end } \\
\text { (clone name) }\end{array}$ & $\begin{array}{l}\text { Region start } \\
\text { (bp) }\end{array}$ & $\begin{array}{l}\text { Region end } \\
\text { (bp) }\end{array}$ & $\begin{array}{l}\text { Region start } \\
\text { (cytogenetic } \\
\text { band) }\end{array}$ & $\begin{array}{l}\text { Region end } \\
\text { (cytogenetic } \\
\text { band) }\end{array}$ & $\begin{array}{l}\text { Size } \\
(\mathrm{Mb})\end{array}$ \\
\hline \multicolumn{8}{|l|}{$B 42-11$} \\
\hline \multicolumn{8}{|l|}{ Gains } \\
\hline 7 & CTB-164D18 & RP4-725G10 & 178219 & 56275548 & $7 p 22$ & 7p11.2 & 56.1 \\
\hline 8 & RP11-338B22 & CTD-2115H11 & 477653 & 43438715 & 8p23.3 & $8 p 11.1$ & 42.9 \\
\hline \multicolumn{8}{|l|}{ Losses } \\
\hline 8 & RP11-114M5 & $\mathrm{RP} 11-24 \mathrm{H} 3$ & 59452746 & 99366374 & $8 q 12.1$ & $8 q 22.2$ & 39.9 \\
\hline 10 & CTC-306F7 & RP11-124011 & 249607 & 42829196 & $10 p 15$ & $10 q 11.2$ & 42.6 \\
\hline \multicolumn{8}{|l|}{$B 42-16$} \\
\hline \multicolumn{8}{|l|}{ Gains } \\
\hline 8 & RP11-45M12 & RP11-263C6 & 3889636 & 29104558 & 8p23 & $8 p 12$ & 25.2 \\
\hline 8 & RP11-350F16 & CTC-489D14 & 47816618 & 146028921 & $8 p 11.1$ & $8 q 24.3$ & 98.2 \\
\hline 12 & RP11-438N16 & CTC-221K18 & 112653797 & 132282931 & $12 q 24.1$ & $12 q 24.3$ & 19.6 \\
\hline 13 & RP11-264F20 & RP11-245B11 & 46538919 & 113940806 & $13 q 14$ & $13 q 34$ & 67.4 \\
\hline$x$ & RP11-457M7 & RP5-966K21 & 2789811 & 57960019 & Xp22.33 & Xp11.21 & 55.2 \\
\hline \multicolumn{8}{|l|}{ Losses } \\
\hline 4 & RP11-164P12 & СТC-963K6 & 191030215 & 191076731 & $4 q 31.3$ & $4 q 35.2$ & 38.3 \\
\hline 10 & СTC-306F7 & RP11-37P5 & 249607 & 16206799 & $10 p 15$ & $10 p 13$ & 16.0 \\
\hline$x$ & RP13-34C21 & RP11-218L14 & 62268206 & 154713754 & Xcen & Xqter & 92.4 \\
\hline
\end{tabular}

B42-11. In B42-16, gains on chromosomes 8, 12 and 13 and losses on chromosomes 4, 10 and $\mathrm{X}$ were detected. An isochromosome 8q, which was already seen in SKY, became apparent in the cell lines B42-11, B42-16 and the parent cell line B42-htLG.

\section{Quantitative RT-PCR}

Transcriptional expression of the candidate genes Has2, Grid1, Wnt1, Arf3, Cpm, Tbx3, Tbx5 and Ret was determined by quantitative real-time PCR (Table 2). Ret, which usually is not expressed in epithelial breast cells (Esseghir et al. 2007), was clearly overexpressed in both cell lines, B42-11 and B42-16. Also Has2 and Gridl were overexpressed in B42-11 and B42-16 relative to B42-htLG. Expression of the gene Wntl was not seen at all in B42-11, whereas in B42-16 it was detected. A slight overexpression of Cpm was found in B42-16, whilst in the same cell line Tbx5 was not expressed at all (Table 2).

\section{Cloning of aberrant gene products}

In order to identify the fusion partners of the rearranged genes Has2 and Grid1, we used RACE PCR followed by sequencing of the resulting amplification products. With respect to the breakpoints of chromosomes 8 and 10, it turned out that a part (exons 3-16) of the gene Gridl (10q23.1-23.2) was fused to an intronic sequence of the gene $Z h x 2$ (8q24.13), which is located $\sim 1 \mathrm{Mb}$ distal to Has2 (8q24.13). RACE amplification of Has 2 revealed a breakpoint between exons 2 and 3 of the gene, but it was not possible to map the fusion sequence to a particular gene. However, neither $5^{\prime}$ RACE using gene-specific primers binding within exons 1 and 2 of Has 2 nor $3^{\prime}$-RACE using primers specific for sequences of exons 1 and 2 of Gridl resulted in successful amplification.

\section{TMA analysis}

The prevalence of rearrangements of the genes Gridl, Has 2 and Ret was determined by FISH using breakpoint-specific probes on a TMA comprising 70 mostly high-grade invasive ductal breast cancer cases. Every section (duplicate cores) was scored for separated (rearranged) FISH signals (Fig. 3). Twenty-eight percentage (19 out of 68 cases) of cases showed alteration of Has2 (rearrangement or copy number amplification), $15 \%$ (10 out of 67) rearrangement of Gridl and 13\% (8 out of 62) rearrangement of Ret (Table 4).

\section{In silico validation of candidate genes in a public available gene expression set}

The dataset was stratified according to grade (BloomRichardson), nodal status and ER status. Group-wise gene expressions of the genes Ret, Has 2 and Gridl were statistically tested.

Expression of Has 2 was significantly increased in grade 3 cases compared with grade 1 and 2 cases ( $P$ value: 0.035$)$. Gridl showed elevated expression in grade 3 compared with low-grade (grade 1 and grade 2 cases combined, $P$ value: 0.03 ) and in node-positive 


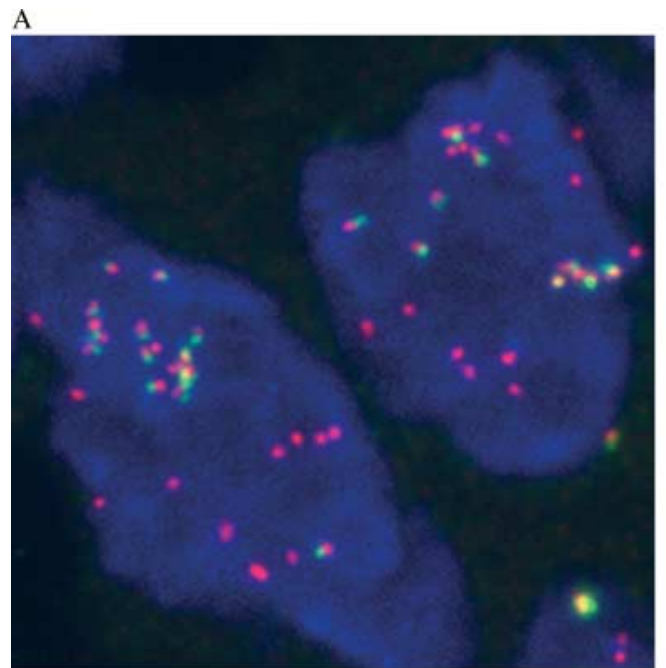

$\mathrm{C}$

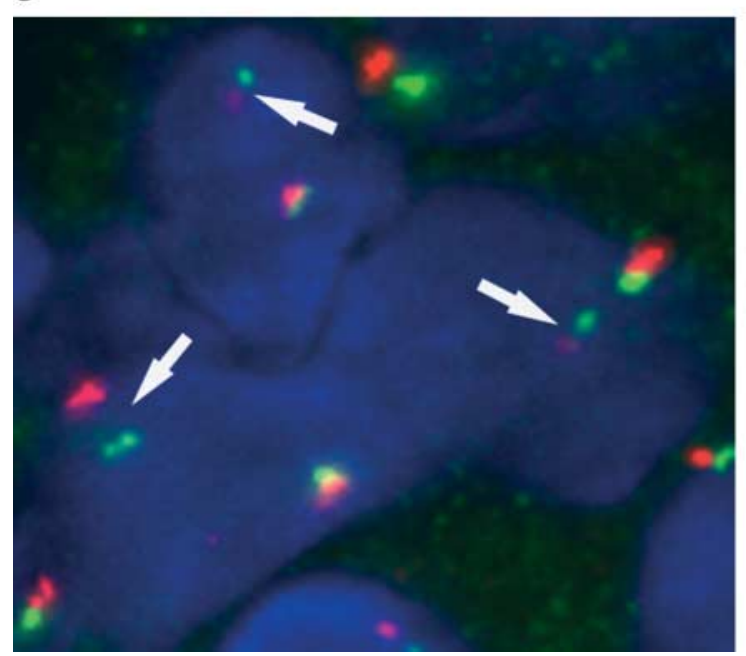

B

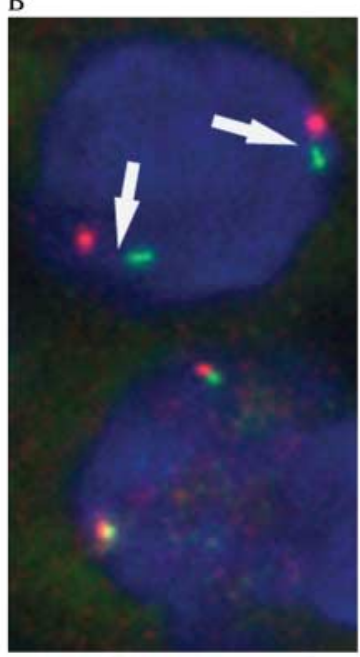

D

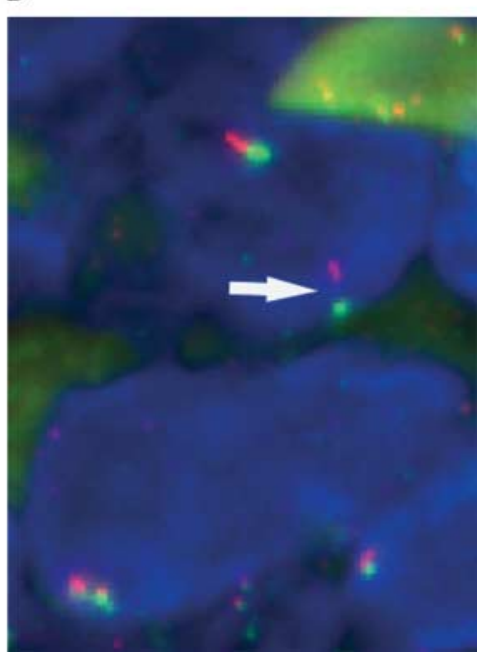

Figure 3 Fluorescence in situ hybridisation on a FFPE breast cancer tissue array. FISH probes (BACs RP11-115M9, red and RP11-497014, green) flanking the chromosomal breakpoint of Has2 in B42-16 were hybridised onto FFPE breast cancer tissues. (A) Two polyploid cells of a breast cancer specimen with multiple red FISH signals representing a high level amplification. (B) Two breast cancer cells from which the upper exhibits a rearrangement of Has2 (split red and green signals, indicated by white arrow) and the lower shows a normal hybridisation pattern (fused signals). (C) A rearrangement of grid1 is demonstrated by split FISH signals (indicated by white arrow) in a breast cancer cell. (D) A rearrangement of the ret locus is indicated by split FISH signals (indicated by white arrow) in a breast cancer cell.

grade $1 / 2$ compared with node-negative grade $1 / 2$ cases ( $P$ values: 0.007 and 0.03$)$. Expression levels of the Ret gene were significantly higher ( $P$ value: 0.04$)$ in ER-positive cases compared with ER-negative cases. Plots of results are given in Supplementary data, see section on supplementary data (section 1).

\section{Discussion}

A combined approach of high-resolution breakpoint analysis of marker chromosomes, PCR-based characterisation of chromosomal breakpoints and FISH was used to investigate chromosomal rearrangements and changes in expression of resulting candidate genes in two radiation-transformed cell lines (B42-11 and B42-16). A significant prevalence of the alterations which we identified from an in vitro model was demonstrated by FISH on a set of clinical breast cancers. Furthermore, we could show by in silico expression analysis that the genes Has2, Gridl and Ret are differentially expressed in clinically relevant groups of breast cancers.

The parent cell line B42-htLG did not induce tumours in nude mice and showed a stable karyotype $47, \mathrm{XX}, \mathrm{i}(8)(\mathrm{q})$. The isochromosome $8 \mathrm{q}$ has already been reported to be associated with an immortal phenotype 
Table 4 Summary of interphase FISH results on a breast cancer tissue microarray (TMA)

\begin{tabular}{|c|c|c|c|c|}
\hline Gene & $\begin{array}{l}\text { BAC/YAC clones used } \\
\text { as DNA probes }\end{array}$ & $\begin{array}{l}\text { Nr. of tumour } \\
\text { tissues } \\
\text { analysed }\end{array}$ & $\begin{array}{l}\text { Nr. of cases } \\
\text { with gene } \\
\text { rearrangement } \\
(\%)\end{array}$ & Cases with gene alteration (position on array) \\
\hline Grid1 & $\begin{array}{l}\text { RP11-369M20 } \\
\text { RP11-711N15 }\end{array}$ & 67 & $10(15)$ & $\begin{array}{l}\text { A6 }{ }^{\mathrm{CIS} / \mathrm{HER}}, \mathrm{C} 9^{\mathrm{ID} / \mathrm{AR} / \mathrm{HER}}, \mathrm{E} 4^{\mathrm{ID} / \mathrm{AR} / \mathrm{ER} / \mathrm{PR}}, \\
\mathrm{E} 6^{\mathrm{ID} / \mathrm{ER} / \mathrm{HER}}, \mathrm{E} 14^{\mathrm{ID} / \mathrm{HER}}, \mathrm{G} 9^{\mathrm{ID} / \mathrm{HER}}, \mathrm{G} 11^{\mathrm{ID}}, \\
\mathrm{G} 15^{\mathrm{ID} / \mathrm{AR} / \mathrm{ER}}, \mathrm{I} 6^{\mathrm{IL} / \mathrm{HER}}, \mathrm{I} 7^{\mathrm{ID} / \mathrm{M}}\end{array}$ \\
\hline Has2 & $\begin{array}{l}\text { RP11-115M9 } \\
\text { RP11-497014 }\end{array}$ & 68 & $19^{\star}(28)$ & 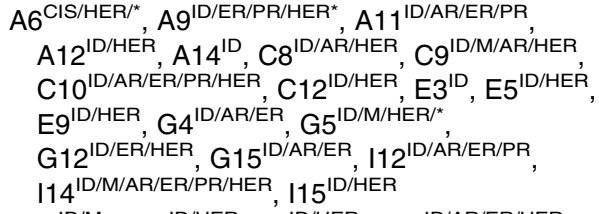 \\
\hline Ret & $313 \mathrm{~F} 4214 \mathrm{H} 10$ & 62 & $8(13)$ & $\begin{array}{l}\mathrm{A} 14^{\mathrm{ID} / \mathrm{M}}, \mathrm{C} 12^{\mathrm{ID} / \mathrm{HER}}, \mathrm{E} 9^{\mathrm{ID} / \mathrm{HER}}, \mathrm{E} 13^{\mathrm{ID} / \mathrm{AR} / \mathrm{ER} / \mathrm{HER}}, \\
\mathrm{G} 9^{\mathrm{ID} / \mathrm{HER}}, \mathrm{G} 12^{\mathrm{ID} / \mathrm{ER} / \mathrm{HER}}, \mathrm{I} 2^{\mathrm{ID} / \mathrm{AR} / \mathrm{ER} / \mathrm{PR}} \\
113^{\mathrm{ID} / \mathrm{AR} / \mathrm{ER} / \mathrm{PR} / \mathrm{HER}}\end{array}$ \\
\hline
\end{tabular}

$\mathrm{M}$, metastasising tumour: either N1-3 or M1; AR, androgene receptor-positive case; ER, estrogene receptor-positive case; $\mathrm{PR}$, progesterone receptor-positive case; HER, HER2/neu amplification; ID, invasive ductal carcinoma; IL, invasive lobular carcinoma; CIS, ductal carcinoma in situ.

*Three cases showed an amplified HAS2 signal instead of a translocation.

of epithelial breast cells (Caruso et al. 2001). Consequently, the marker chromosomes in the transformed cell lines (Table 1) must have developed during radiation-induced malignant transformation and can be attributed to the tumourigenic phenotype of the cells. The complex nature of the rearrangements of the marker chromosomes M16-3 and M16-4 in the cell line B42-16 could be classified as a translocation between chromosomes 10 and 12 with an additional terminal deletion of $10 \mathrm{p}$ and a deletion of the gene $T b \times 5$ on 12q24.2. The lack of expression of Tbx5 (Table 2) supports the idea that copy number alterations often lead to altered gene expression of the affected gene.

The candidate genes identified from breakpoint analysis showed a deregulated expression except for Tbx3, Arf3 and Cpm (Table 2) indicating the importance of the identified gene rearrangements for gene expression in these cell lines. Gridl represents a subunit of the glutamate receptor GRID1 (Haas et al. 2005), Has 2 a Hyaluronan synthase (Haas et al. 2005), Arf3 an ADP-ribosylation factor (Hirai et al. 1996), Cpm a carboxypeptidase (Pessoa et al. 2002) and Tbx5 a T-box transcription factor (Hatcher et al. 2001). Wht 1 expression and subsequent activation of the Notch signalling pathway have already been reported to play a significant role in breast carcinogenesis (Collu \& Brennan 2007), whilst some of the other candidate genes have not been reported in conjunction with breast carcinogenesis so far. Of particular interest are the rearrangements of Has2, Gridl and Ret, because of their significantly elevated expression in the transformed cell lines.
Has 2 was translocated one megabase distal to the Gridl-containing region on chromosome 10. The breakpoint of Has 2 occurred between exon 2 and 3 affecting the largest (putatively cytosolic) domain of the protein. The DNA sequence fused to Has 2 could not be ascribed to a particular gene, and therefore, the mechanism of activation in the B42-16 cell line remains unclear. Has 2 encodes for a high molecular weight hyaluronan (Itano et al. 1999), which at increased expression levels reduces contact inhibition of cell growth and promotes cell migration and thus contributing to features of a transformed phenotype such as anchorage-independent and invasive growth (Itano et al. 2002, Zoltan-Jones et al. 2003). Consequently, in breast cancer, an elevated Has 2 expression was shown to be associated with increased cellular proliferation and an invasive phenotype (Udabage et al. 2005a,b, Cook et al. 2006). In our studied set of primary breast cancers, Has 2 was altered in $28 \%$ of cases (TMA), and expression was elevated in the grade 3 tumours of the analysed in silico validation set (Miller et al. 2005). This is in accordance with another study correlating Has 2 overexpression with an unfavourable outcome (Tammi et al. 2008). In this context, gene rearrangement of Has2 represents a novel mechanism of its activation and offers considerable potential as a therapeutic target in breast cancer.

The location of the chromosomal breakpoint within the Gridl gene (between exon 2 and 3) indicates an alteration of the ligand-binding N-terminal domain of the resulting protein. Gridl belongs to a group of glutamate receptors that were believed to exclusively 
play a role in the central nervous system (CNS). However, it was recently shown that the glutamatergic system is also involved outside the CNS in malignant processes (Rzeski et al. 2002, Haas et al. 2005, Kalariti et al. 2005).

From a clinical perspective rearrangement of Gridl in a substantial subset of breast cancers and elevated expression in grade 3 and low-grade lymphnode-positive breast cancers makes the gene, which is reported in this context for the first time attractive as a potential tumour marker.

Another candidate gene from this study is the receptor tyrosine kinase (TK) Ret, which was surprisingly overexpressed in both transformed cell lines, although only B42-11 exhibited a rearrangement of the gene. In addition both cell lines expressed the ligand-binding (EC) and TK domains of Ret at almost similar levels, which is remarkable in case of B42-11, since in papillary thyroid carcinomas with RET/PTC rearrangement usually only the TK domain is expressed (Ciampi \& Nikiforov 2007). Thus, it is likely that in breast cells Ret is activated by a different mechanism or also an activation of the Ret-EC domain occurs in case of a rearrangement. In a study on mostly Her2/PR-positive breast cancers, it was recently reported that Ret is co-expressed with its co-receptor Gfral and its ligand GDNF (Esseghir et al. 2007), and another study demonstrated overexpression of Ret in breast cancer cell lines showing RET-induced anchorage-independent growth (Boulay et al. 2008). Both studies suggest interaction of RET with the ER pathway. This is supported by the finding that Ret expression is associated with positive ER status in the expression set from Miller et al. (2005). With regard to RET as a therapeutic target for TK inhibitors such as sunitinhib, activation by rearrangement might be of particular interest. The above-mentioned studies would not pick up Ret expression after rearrangement due to the methodology they have used. Therefore, Ret expression in breast cancer is likely to be underestimated, and usage as a therapeutic target or diagnostic/prognostic marker should be taken into consideration.

Our study demonstrated that the molecular analysis of chromosomal breakpoints in radiationtransformed epithelial breast cell lines is able to reveal novel breast cancer candidate genes and that rearrangement of these lead to altered gene expression. Prevalence of rearrangement and subsequent upregulation of Gridl, Has 2 and Ret could be validated in sporadic breast cancer. This provides evidence that genomic alterations and gene rearrangements in particular can be used for the identification of attractive candidates in diagnosis and treatment of breast cancer.

\section{Supplementary data}

This is linked to the online version of the paper at http://dx. doi.org/10.1677/ERC-09-0065.

\section{Declaration of interest}

The authors declare that there is no conflict of interest that could be perceived as prejudicing the impartiality of the research reported.

\section{Funding}

Dr Chris Jones for supplying the packaging cell line $\psi$-CRIP with the pBABE-hTERT vector. Dr Cordelia Langford and the Wellcome Trust Sanger Institute Microarray Facility for supplying the $1 \mathrm{Mb}$ arrays. The project was partly funded by the Bundesamt fuer Strahlenschutz (project code: S30004).

\section{Acknowledgements}

Work on the manuscript was finished at the Department of Histopathology, Imperial College London, Hammersmith Hospital, Du Cane Road, W12 0NN London, UK.

\section{References}

Albertson DG, Collins C, Mccormick F \& Gray JW 2003 Chromosome aberrations in solid tumors. Nature Genetics 34 369-376.

Backx L, Van Esch H, Melotte C, Kosyakova N, Starke H, Frijns JP, Liehr T \& Vermeesch JR 2007 Array painting using microdissected chromosomes to map chromosomal breakpoints. Cytogenetic and Genome Research 116 158-166.

Boulay A, Breuleux M, Stephan C, Fux C, Brisken C, Fiche M, Wartmann M, Stumm M, Lane HA \& Hynes NE 2008 The Ret receptor tyrosine kinase pathway functionally interacts with the ERalpha pathway in breast cancer. Cancer Research 68 3743-3751.

Caruso JA, Reiners JJ Jr, Emond J, Shultz T, Tainsky MA, Alaoui-Jamali M \& Batist G 2001 Genetic alteration of chromosome 8 is a common feature of human mammary epithelial cell lines transformed in vitro with benzo[a]pyrene. Mutation Research 473 85-99.

Ciampi R \& Nikiforov YE 2007 RET/PTC, rearrangements BRAF mutations in thyroid tumorigenesis. Endocrinology 148 936-941.

Climent J, Garcia JL, Mao JH, Arsuaga J \& Perez-losada J 2007 Characterization of breast cancer by array comparative genomic hybridization. Biochemistry and Cell Biology 85 497-508. 
Collu GM \& Brennan K 2007 Cooperation between Wnt and Notch signalling in human breast cancer. Breast Cancer Research 9105.

Cook AC, Chambers AF, Turley EA \& Tuck AB 2006

Osteopontin induction of hyaluronan synthase 2 expression promotes breast cancer malignancy. Journal of Biological Chemistry 281 24381-24389.

Darai-Ramqvist E, De Stahl TD, Sandlund A, Mantripragada K, Klein G, Dumanski J, Imreh S \& Kost-Alimova M 2006 Array-CGH and multipoint FISH to decode complex chromosomal rearrangements. BMC Genomics 7330.

Esseghir S, Todd SK, Hunt T, Poulsom R, Plaza-Menacho I, Reis-Filho JS \& Isacke CM 2007 A role for glial cell derived neurotrophic factor induced expression by inflammatory cytokines and RET/GFR alpha 1 receptor up-regulation in breast cancer. Cancer Research 67 11732-11741.

Ferguson-Smith MA 1997 Genetic analysis by chromosome sorting and painting: phylogenetic and diagnostic applications. European Journal of Human Genetics 5 253-265.

Fiegler H, Carr P, Douglas EJ, Burford DC, Hunt S, Scott CE, Smith J, Vetrie D, Gorman P, Tomlinson IP et al. 2003 DNA microarrays for comparative genomic hybridization based on DOP-PCR amplification of BAC and PAC clones. Genes Chromosomes and Cancer 36 361-374.

Frohman MA, Dush MK \& Martin GR 1988 Rapid production of full-length cDNAs from rare transcripts: amplification using a single gene-specific oligonucleotide primer. PNAS 85 8998-9002.

Haas HS, Pfragner R, Siegl V, Ingolic E, Heintz E \& Schauenstein K 2005 Glutamate receptor-mediated effects on growth and morphology of human histiocytic lymphoma cells. International Journal of Oncology 27 867-874.

Hanahan D \& Weinberg RA 2000 The hallmarks of cancer. Cell 100 57-70.

Hatcher CJ, Kim MS, Mah CS, Goldstein MM, Wong B, Mikawa T \& Basson CT 2001 TBX5 transcription factor regulates cell proliferation during cardiogenesis.

Developmental Biology 230 177-188.

Hiller B, Bradtke J, Balz H \& Rieder H 2005 CyDAS: a cytogenetic data analysis system. Bioinformatics 21 1282-1283.

Hirai M, Kusuda J \& Hashimoto K 1996 Assignment of human ADP ribosylation factor (ARF) genes ARF1 and ARF3 to chromosomes 1q42 and 12q13, respectively. Genomics 34 263-265.

Itano N, Sawai T, Yoshida M, Lenas P, Yamada Y, Imagawa M, Shinomura T, Hamaguchi M, Yoshida Y, Ohnuki Y et al. 1999 Three isoforms of mammalian hyaluronan synthases have distinct enzymatic properties. Journal of Biological Chemistry 274 25085-25092.

Itano N, Atsumi F, Sawai T, Yamada Y, Miyaishi O, Senga T, Hamaguchi M \& Kimata K 2002 Abnormal accumulation of hyaluronan matrix diminishes contact inhibition of cell growth and promotes cell migration. PNAS 99 3609-3614.

Kalariti N, Pissimissis N \& Koutsilieris M 2005 The glutamatergic system outside the CNS and in cancer biology. Expert Opinion on Investigational Drugs 14 1487-1496.

Livak KJ \& Schmittgen TD 2001 Analysis of relative gene expression data using real-time quantitative PCR and the 2(-Delta Delta $C(\mathrm{~T}))$ method. Methods 25 402-408.

Miller LD, Smeds J, George J, Vega VB, Vergara L, Ploner A, Pawitan Y, Hall P, Klaar S, Liu ET et al. 2005 An expression signature for $\mathrm{p} 53$ status in human breast cancer predicts mutation status, transcriptional effects, and patient survival. PNAS 102 13550-13555.

Neuvial P, Hupe P, Brito I, Liva S, Manie E, Brennetot C, Radvanyi F, Aurias A \& Barillot E 2006 Spatial normalization of array-CGH data. BMC Bioinformatics 7264.

Neve RM, Chin K, Fridlyand J, Yeh J, Baehner FL, Fevr T, Clark L, Bayani N, Coppe JP, Tong F et al. 2006 A collection of breast cancer cell lines for the study of functionally distinct cancer subtypes. Cancer Cell $\mathbf{1 0}$ 515-527.

Ng BL \& Carter NP 2006 Factors affecting flow karyotype resolution. Cytometry. Part A 69 1028-1036.

Ozaki S, Ikeda S, Ishizaki Y, Kurihara T, Tokumoto N, Iseki M, Arihiro K, Kataoka T, Okajima M \& Asahara T 2005 Alterations and correlations of the components in the Wnt signaling pathway and its target genes in breast cancer. Oncology Reports 14 1437-1443.

Pessoa LG, Da Silva ID, Baptista HA, Pesquero JL, Paiva AC, Bader M \& Pesquero JB 2002 Molecular structure and alternative splicing of the human carboxypeptidase $\mathrm{M}$ gene. Biological Chemistry 383 263-269.

Platonova N, Scotti M, Babich P, Bertoli G, Mento E, Meneghini V, Egeo A, Zucchi I \& Merlo GR 2007 TBX3, the gene mutated in ulnar-mammary syndrome, promotes growth of mammary epithelial cells via repression of p19ARF, independently of p53. Cell and Tissue Research 328 301-306.

Rhoden KJ, Johnson C, Brandao G, Howe JG, Smith BR \& Tallini G 2004 Real-time quantitative RT-PCR identifies distinct c-RET, RET/PTC1 and RET/PTC3 expression patterns in papillary thyroid carcinoma. Laboratory Investigation 84 1557-1570.

Riches AC, Herceg Z, Bryant PE, Stevens DL \& Goodhead DT 1997 Radiation-induced transformation of SV40-immortalized human thyroid epithelial cells by single exposure to plutonium alpha-particles in vitro. International Journal of Radiation Biology 72 515-521.

Romanov SR, Kozakiewicz BK, Holst CR, Stampfer MR, Haupt LM \& Tlsty TD 2001 Normal human mammary epithelial cells spontaneously escape senescence and acquire genomic changes. Nature 409 633-637. 
Rzeski W, Ikonomidou C \& Turski L 2002 Glutamate antagonists limit tumor growth. Biochemical Pharmacology 64 1195-1200.

Takahashi M, Buma Y, Iwamoto T, Inaguma Y, Ikeda H \& Hiai H 1988 Cloning and expression of the ret protooncogene encoding a tyrosine kinase with two potential transmembrane domains. Oncogene 3 571-578.

Tammi RH, Kultti A, Kosma VM, Pirinen R, Auvinen P \& Tammi MI 2008 Hyaluronan in human tumors: pathobiological and prognostic messages from cell-associated and stromal hyaluronan. Seminars in Cancer Biology 18 288-295.

Udabage L, Brownlee GR, Nilsson SK \& Brown TJ $2005 a$ The over-expression of HAS2, Hyal-2 and CD44 is implicated in the invasiveness of breast cancer. Experimental Cell Research 310 205-217.

Udabage L, Brownlee GR, Waltham M, Blick T, Walker EC, Heldin P, Nilsson SK, Thompson EW \& Brown TJ $2005 b$ Antisense-mediated suppression of hyaluronan synthase 2 inhibits the tumorigenesis and progression of breast cancer. Cancer Research 65 6139-6150.

Unger K, Zitzelsberger H, Salvatore G, Santoro M, Bogdanova T, Braselmann H, Kastner P, Zurnadzhy L, Tronko N, Hutzler P et al. 2004 Heterogeneity in the distribution of RET/PTC rearrangements within individual post-Chernobyl papillary thyroid carcinomas. Journal of Clinical Endocrinology and Metabolism 89 4272-4279.

Venkatraman ES \& Olshen AB 2007 A faster circular binary segmentation algorithm for the analysis of array CGH data. Bioinformatics 23 657-663.

Wyllie FS, Jones CJ, Skinner JW, Haughton MF, Wallis C, Wynford-Thomas D, Faragher RG \& Kipling D 2000 Telomerase prevents the accelerated cell ageing of Werner syndrome fibroblasts. Nature Genetics 24 16-17.

Zitzelsberger H, Lehmann L, Hieber L, Weier HU, Janish C, Fung J, Negele T, Spelsberg F, Lengfelder E, Demidchik EP et al. 1999 Cytogenetic changes in radiation-induced tumors of the thyroid. Cancer Research 59 135-140.

Zitzelsberger H, Bruch J, Smida J, Hieber L, Peddie CM, Bryant PE, Riches AC, Fung J, Weier HU \& Bauchinger M 2001 Clonal chromosomal aberrations in simian virus 40-transfected human thyroid cells and in derived tumors developed after in vitro irradiation. International Journal of Cancer 96 166-177.

Zoltan-Jones A, Huang L, Ghatak S \& Toole BP 2003 Elevated hyaluronan production induces mesenchymal and transformed properties in epithelial cells. Journal of Biological Chemistry 278 45801-45810. 